\title{
Closing panel
}

\author{
Chair: Herman P. Spruijt \\ Royal Brill Academic Publishers, Leiden, The Netherlands, and vice president of IPA, Geneva, \\ Switzerland
}

Dr. Albrecht Hauff (CEO, Thieme Verlag KG, Stuttgart) states that he has doubts whether a change from a competition-based publishing system to a state- or university-run system would be a change for the better. In his opinion, the neutrality of publishers with regards to content is very important. Further, he discusses the question how scientific communication can be improved all the way to society at large. Dr. Hauff does not consider this task a primary function of scientific publishing as other players already fulfil that task. But if today, it is felt necessary that scientific information has to be communicated faster to the public, scientific publishers should be involved. Moreover, he stresses the importance of copyright protection with remembering that a lesser protection would discourage publishing activities, which can lead to the end of the scientific monograph. Moreover, he clearly states that it is unlikely, that Open Access will lead to a reduction of costs. Finally, Dr. Hauff reminds that publishers will have to add value to the dissemination of science, because otherwise, they would not be needed anymore.

Professor Dr. Jürgen Renn (Max Planck Institute for the History of Science, Berlin) appeals that publishers should regard scientists as customers and not as competitors. He agrees with Dr. Hauff that added value and investments are necessary and that there is no reason that the future system will be less expensive. But he blames the publishing industry to be too conservative. Professor Dr. Renn suggests that the publishing business should be guided by the most innovative and advanced scientists. He gives the example of small scientific communities that already use improved mechanisms of filtering and quality control. Further, he emphasizes the importance of adding or linking primary data to published papers for the purpose of quality control. He proposes that the publishing industry should shift their investments from conserving the old system to a new infrastructure with value added services for innovative science activities. Lastly, he emphasizes that not only STM, but also cultural heritage is an important area of new scholarly publishing models.

Professor Dr. Klaus Saur (Walter de Gruyter C.o. KG, Berlin) explains that publishers still play a very important role. But he sees this role endangered by recent legislation and public funding policies. Due to the recent developments of free online content, he warns that publications, which were published for decades or centuries, might have to be discontinued. Therefore, he appeals to publishers to protect copyright as much as possible. Regarding the comments of Dr. Renn, he points out that scientists do become competitors as soon as they deliver all their content in an open access format. Further, he explains that budget reductions in libraries are an important aspect of the problem. Finally, Professor Dr. Saur warns that all these developments will lead to a reduction in quality of information.

The general debate in the closing panel was largely driven by the issue of Open Access. The pros and cons in the lively discussion showed a wide spectrum of opinions.

The base for the discussion was Prof. Dr. Jürgen Renn's demand to publishers to allow open access models. Prof. Dr. Renn explained that open access is the wish of the customers, the scientists, and that it 
is the enabler for a new form of science communication. The discussion was continued by Jan Velterop (Springer), who pointed out that it is very easy to make information freely available. Therefore, Velterop claimed, there are no good arguments against open access. In this context, Prof. Dr. Renn emphasised that not only information is closed up currently, but that publishers invest to close up information. Dr. Matthew Cockerill (BioMed Central), supporting Prof. Dr. Renn's initial argument, explained that open access is "the only way to allow the full resources of academia to throw that creativity at finding the best ways to discover content and put that content in context".

Prof. Dr. Klaus Saur pointed out that a lot of content might be excluded from publication when an open access model is forced because its publishing costs cannot be recovered. Further, David Hoole (Nature Publishing Group) claimed that an author-pay-open-access model would be unfair if a journal has a much larger number of readers than authors, as publication fees per article might be beyond 20,000 Euro. Sally Morris (ALPSP) indicated that latest research shows that the argument, that open access raises the impact of an article seems to be false.

Willy Stalmans stated that FEBS (and many other Scientific Societies), if they were to adopt Open Access publishing, would lose their income for funding courses, congresses and fellowships, leaving European bio-scientists homeless and impoverished. In the best scenario, some of those activities might be taken over by, e.g., the E.U. But scientists should then face the consequences, aptly worded by the physicist Sir Ernest Rutherford (1926): "It is essential for men of science to take an interest in the administration of their own affairs, or else the professional civil servant will step in - and then the Lord help you!"

Moreover, Peter Gregory (Royal Society of Chemistry) warns that open access might reduce the quality of journals when "volume is good for profit". Finally, Bianca Gerlinger (van Tulleken) called open access a form of "content communism".

Pieter Bolman (STM) clarified that the publishing industry should carefully listen to the scientific community and choose the best business model with it to make it possible. He warns that the industry should not per se defend the status quo.

In the final statement, Herman P. Spruijt (Royal Brill Academic Publishers) points out that Open Access business models should not be confused with the already achieved effects of digital distribution: scientist have at their fingertips more information immediately available then ever and we experience with more than one business model already. The question is now: Who in the information chain should pay the bill? We seem to agree that more than one model can be around and that an abrupt change is not the best solution for the academic community.

Despite all the energy and investments publishers are devoting to change their role, if they are not seen as adding enough value to the chain and not seen as proactive enough, authors, libraries and funding agencies will vote with their feet: technology is not the prerogative of publishers only, but available to all players.

\section{Closing remarks}

\section{Herman P. Spruijt}

\section{Publishing is adding value}

The only way to continue the role as publisher is 'making the difference' by continuingly adding new value to the communication chain. 
In the past this was mainly printing and distribution. Nowadays, amongst other functions like certification, etc., the nature of publishing is to assure information can be found quickly and efficiently by facilitating more and better access, allowing deep searching, etc.

Not that the publishers did not act in the last 10 years: nobody will deny that there are more articles than ever downloaded and that the price per download has been reduced dramatically (the price spiral in the serial business is broken in the end), but unfortunately that is not enough: Libraries are still facing the problem of funding, because the output of scientific research in articles and other types of information continues to grow explosively.

Publishers also were able to support price differentiation: Create more ways of payment than in the past: pay per use/view, pay per subscription, bundle or even gain access to the complete database/platform of a publisher. We now even have institutionalised pricing per region (Hinari Project of the WHO, Agora Project of the FAO, etc.).

\section{Open Access as a principle and a business model}

Open Access has been a hot and sometimes emotional issue during this conference. It is in the first place a principle: all information should be available too research community without (too much of) a barrier.

Of course Open Access is also a business model (who pays: the author or the user?).

History and the various presentations and discussions during the conference allow the observation, that one business model can nicely live next to another. Actually quite some participants felt that no revolution is needed but that the scientific community is served by gradual change.

\section{Co-existence of business models}

One should bear in mind that this is not no too new either! Also in the recent past more than one model existed in harmony: Not too long ago the US-society publishers requested page charges, paid by the author or his/her institution for inclusion of a article in a journal, since they experienced page/paper limitations. The basis for this habit was that membership fees should be so low that all members could receive the society journal to assure maximum dissemination in the core group of readers. These journals were often distributed for free to the academic libraries and for libraries abroad only postal charges were charged.

This system worked well next to a European system of international journals, which had no page charges but subscriptions and a price-level linked to volume and circulation.

Of course we should mention here also the combined business model for the large subscription journals like Nature and Science, which have different circulation figures and substantial advertising income. We all know that the yearly increase of scientific papers, titles and lack of adequate funding has lead to a dramatic price spiral: cancellations because of higher prices and higher prices as compensation for lower circulation and increase of the number of papers.

\section{Period of uncertainty and change}

Digitalisation and distribution over the Internet have changed the basis for the pricing models and we are now in a logic period of uncertainty, if not chaos, to find out together what the best mix of models, old and new, because or new technology opportunities will be. Hence this and other debates. 


\section{Always important to stay close to the user communities}

The presentations at this conference made it once again clear that publishers should creep even more into the skin of the academic community and try to understand what the academic world needs today because of the quickly changing technology and new generations of computer literate scientists. We were urged to further improve our efficiency, speed and quality. We also agreed that it is very important to harmonise, standardise and link all types of information, and of course work on even more intelligent and efficient search engines and algorithms to facilitate academics to do their work!

We can safely say that, the more efficient the publishers facilitate these wishes in relative harmony (not too much competition, but preferably pre-competitive cooperation (like with DOI and CrossReff)), the less the academic world and libraries feel the need to step into the role of a publisher.

\section{Authors are less dependent on publishers...}

This is even more urgent, because nowadays each author is in the driving seat and able to disseminate his/her work over the web on his/her own and so 'votes with his/her feet'. Preprint servers, all kinds of repositories and (publishers) platforms are happy to receive and host good quality content.

Technology did not stop at the door of the publishers. As we learned from several presentations, libraries and academic institutions are experimenting as well. More and more options arise, all based on technology.

If publishers want to recoup the investments made, they better focus on the facilitation of the work flow of the scientist instead of offering technological gadgets and fancy features, because the information chain costs money and somebody has to pay the bill.

Obviously we have not found the ideal solution or even the grail yet. All of us are on a quest, but the Conference showed that this can be done in constructive dialogue. To be continued! 